\title{
Water and salt transport in daily irrigated root zone
}

\author{
C. Dirksen
}

Department of Soil Science and Plant Nutrition, Wageningen Agricultural University, P.O. Box 8005, NL 6700 EC Wageningen, Netherlands

Received 28 April 1987; accepted 11 June 1987

Key words: high-frequency irrigation, leaching fraction, root water uptake, salinity, soil water potentials, hysteresis

\begin{abstract}
With closed, high-frequency irrigation systems water gifts can be tailored to the instant needs of plants. To be able to do this optimally, one must understand how plants interact with their environment. To study water uptake under a variety of non-uniform conditions in the root zone, lucerne was grown in laboratory soil columns with automated gamma ray attenuation, tensiometer and salinity sensor equipment to measure soil water contents, pressure potentials and osmotic potentials, respectively. The columns were irrigated with water of different salinity at various frequencies and leaching fractions. This paper presents mainly results obtained in a column irrigated daily with water of conductivity $0.33 \mathrm{~S} / \mathrm{m}\left(h_{0}=-13.2\right.$ $\mathrm{m})$ at a target leaching fraction of 0.08 . This includes the drying and wetting patterns under daily irrigations in deficit and excess of evapotranspiration, respectively. After 230 days the salination of the column had still not reached a steady state. Salinity increased rapidly with depth and root water uptake was shallow for the deep-rooting lucerne. Water and salt transport under daily irrigation cannot be described without taking hysteresis of soil water retention into account. The presented data are suitable for testing various water uptake models, once numerical water and salt transport models of the required complexity are operational.
\end{abstract}

\section{Introduction}

Conventional flood irrigation methods, such as border and furrow irrigation, are used at low frequency. With each irrigation the root zone is filled with water. During the first few days after water application, often appreciable amounts of water drain beyond the root zone, the actual quantities depending on the water retention characteristics of the soil. This may result in more leaching than required for salinity control. After the soil profile reaches so-called field capacity, the remaining water is essentially at rest. Water contents then decrease as a result of root water uptake and soil surface evaporation, usually to very low soil water pressure potentials. If 


\section{DIRKSEN}

the irrigation water contains much salt, very low soil water osmotic potentials are attained as well. Unless the next irrigation follows on time, the total soil water potential will become too low for plants to take up sufficient water to prevent yield reduction. In practice, irrigation intervals vary mostly between two to six weeks, depending on climate, soil hydraulic properties, crop salt tolerances, water availability, labour costs, etc.

The water balance of a volume element in the root zone can be expressed by the continuity equation, which for one-dimensional, vertical water transport reduces to (Koorevaar et al., 1983):

$$
\sigma=\frac{\partial \theta}{\partial t}+\frac{\partial q}{\partial z} \text { or } \quad \mathrm{RWU}=\mathrm{RCWC}+\mathrm{DF}
$$

where $\sigma=$ (negative) rate of water uptake (RWU) by roots $\left(\mathrm{m}^{3} \mathrm{~m}^{-3} \mathrm{~s}^{-1}\right), \theta=$ volume fraction of water, usually called volumetric water content $\left(\mathrm{m}^{3} \mathrm{~m}^{-3}\right), t=$ time (s), $q=$ water flux density $\left(\mathrm{m}^{3} \mathrm{~m}^{-2} \mathrm{~s}^{-1}\right)$ and $z=$ vertical coordinate, positive downward $(\mathrm{m})$. The second term is the rate of change of water content (RCWC). The third term, the divergence of the water flux density (DF) is the rate at which the water flux density decreases in the vertical direction. Thus, during irrigation and redistribution DF is dominant; the 'definition' of field capacity implies that DF can be assumed to be zero. The water flux density is described by Darcy's law:

$$
q=-k \frac{\partial H}{\partial z}=-k \frac{\partial h}{\partial z}+k
$$

where $H=h-z=$ hydraulic head $(\mathrm{m}), h=$ pressure head $(\mathrm{m})$, and $k=$ hydraulic conductivity $\left(\mathrm{m} \mathrm{s}^{-1}\right)$. Both $h$ and $k$ are a function of $\theta$; the former is hysteretic, which means that the relationship is different for wetting and drying soil. In general, hysteresis diminishes redistribution and drainage of irrigation water significantly. For further details on the theory of water transport in soils, see Koorevaar et al. (1983).

With high-frequency irrigation methods (Rawlins \& Raats, 1975) it is possible to maintain high soil water contents and potentials, while drainage is still kept low. Plant roots near the soil surface are continually supplied with water and root water uptake tends to be concentrated in the shallow soil layers. Salts contained in the irrigation water are not taken up, but displaced below the most active zone of water uptake. As a result, salinity increases rapidly with depth. As long as the net flux of water is downward, salts contained in the irrigation water will not accumulate in the root zone, although the salinity level may become quite high. The drainage required to prevent yield reduction depends on the crop salt tolerance and can be small, even intermittent, as low as $5 \%$ of the irrigation flux (leaching fraction LF = $0.05)$. Such low leaching fractions can be attained with closed systems that can be operated on demand, with little or no labour costs (automation). This permits uniform areal application of very small amounts of water, regulated by the irrigation system independent of spatial variability of the soil hydraulic properties. In principle, gifts of water can be tailored to the instant needs of plants, but one cannot do 
this unless the interactions of water and salt transport, root water uptake, crop salt tolerances, etc. under these new irrigation regimes are well understood. For a recent review on this subject, see Dirksen (1983).

The interactions of plants with soil water and salinity conditions varying both in space and in time should preferably be investigated under field conditions to make results most directly applicable. Unfortunately, field experiments have many disadvantages. They require great expense and much effort of many people (e.g. Hoffman et al., 1977, 1984a, 1984b). Even then, the obtained information is often mostly of an operational nature and not detailed enough to study fundamental processes. Detail studies as those reported by Dirksen et al. (1979) on the root zone of a single orange tree are scarce. For such experimental programs, conditions are more favourable in the laboratory.

With the above considerations in mind, a two-year experimental programme was carried out with lucerne in six densely instrumented laboratory soil columns. Variation in soil water pressure and osmotic potential distributions was established by varying the quantity and salinity of the irrigation water, as well as the irrigation frequency. During the first phase the columns were irrigated daily with water of different salinity and/or at different leaching fractions. After one column was sampled in great detail and experimental conditions were improved during an interim period, the remaining five columns were irrigated at intervals from 4 to 12 days. Then, all columns received the same total amount of water of the same salinity, except one that received only tap water throughout the entire study. Finally, a number of special studies were performed. Some results of the non-daily irrigation and the special studies were already reported (Dirksen, 1980, 1985; Dirksen \& Raats, 1985). This paper reports results for the daily irrigation. Unless indicated otherwise, they were obtained from the column irrigated at the smallest leaching fraction (target $\mathrm{LF}=$ 0.08 ) with water of EC $0.33 \mathrm{~S} / \mathrm{m}$ (osmotic head $h_{0}=-13.2 \mathrm{~m}$; Dirksen, 1983).

\section{Materials and methods}

Experimental details, including photographs of the experimental apparatus and soil hydraulic properties, are given in the above references, particularly in Dirksen (1985). Here, only a few particulars of the daily irrigation phase are mentioned. The experiments were carried out in six segments $(0.394 \mathrm{~m} \times 0.178 \mathrm{~m} \times 1.07 \mathrm{~m})$ of the soil water-flow model with two-dimensional automatic gamma ray attenuation scanner (Dirksen \& Huber, 1978) to measure soil water contents. Soil water pressure and osmotic potentials were measured with automated tensiometer and salinity sensor equipment. Irrigation water was salinized with equal molar (charge) quantities of $\mathrm{NaCl}$ and $\mathrm{CaCl}_{2}$ and pumped on the soil surface through up to 14 drip points. Drainage was collected via porous filter candles at the bottom maintained at constant pressure head. This pressure head was initially kept too low; it was gradually changed from $-4.0 \mathrm{~m}$ to $-1.5 \mathrm{~m}$. The light intensity at $0.60 \mathrm{~m}$ above the soil surface was about $25 \mathrm{klux}$. The room was kept around $25^{\circ} \mathrm{C}$ and $50 \%$ relative humidity. The lucerne was seeded on J5120 (ordinal date 120, 1975). Daily irrigation was started with tap water $\left(h_{0}=-2.4 \mathrm{~m}\right)$ on $\mathrm{J} 5148$ and changed to saline water of $h_{0}$ 


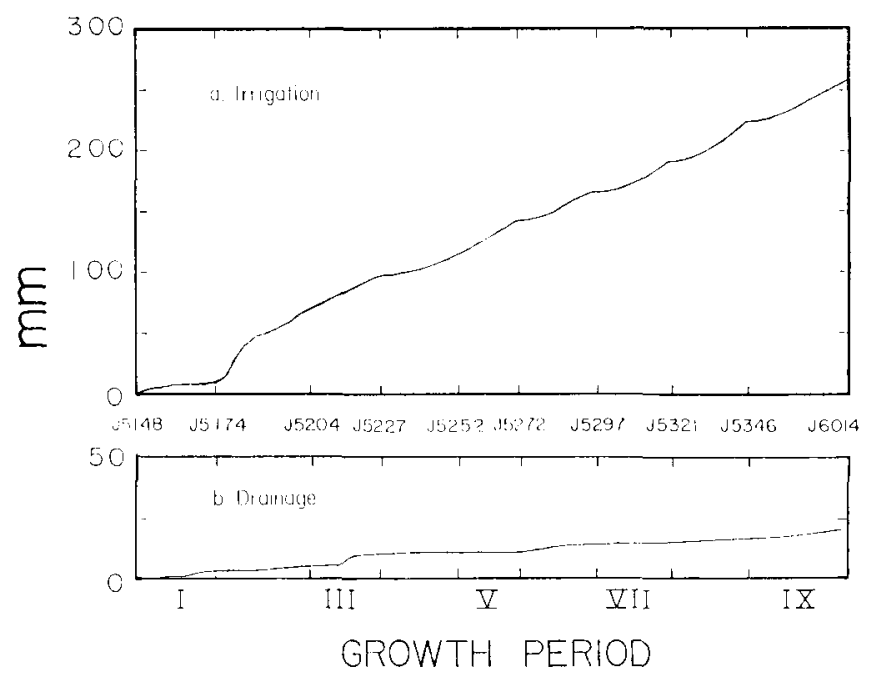

Fig. 1. Cumulative irrigation (a) and drainage (b).

$=-13.2 \mathrm{~m}$ on J5164. The first harvest (I) was on J5174. Thereafter, eight additional growth periods/harvests under daily irrigation followed, most of them lasting about 24 days. The last harvest (IX) on J6014 occurred after 35 days of growth. The lights were on for 16 hours per day and the evaporative demand of the laboratory conditions was quite high. The canopy size increased during a growth period and attained at the top more than twice the cross-sectional area of the soil column $\left(700 \mathrm{~cm}^{2}\right)$. As a result, evapotranspiration (ET) was much higher than anticipated and therefore the columns initially were underirrigated. This became apparent from the ET values for selected days of growth periods IV, V, and VI (Table 1) which were calculated as only unknown component of the water balance of the columns. The daily amounts of irrigation were changed regularly in an effort to stay close to the target $\mathrm{LF}=0.08$ (Fig. 1). The system proved too sluggish to be able to do this without good estimates of ET. Table 1 also lists the dry weight at harvest and the (evapo)transpiration ratio of the same periods. Evaporation was not evaluated separately, but must have been small compared with the large transpiration, because the soil surface was always well covered by the plants.

Table 1. Evapotranspiration on selected days, dry weight, and transpiration ratio of growth periods IV, V, and VI.

\begin{tabular}{|c|c|c|c|c|c|c|c|c|c|}
\hline \multirow{2}{*}{$\begin{array}{l}\text { Growth } \\
\text { period }\end{array}$} & \multirow[b]{2}{*}{ day $\rightarrow$} & \multicolumn{6}{|c|}{ Evapotranspiration (mm) } & \multirow{2}{*}{$\begin{array}{l}\text { Dry } \\
\text { weight } \\
\text { (g) }\end{array}$} & \multirow{2}{*}{$\begin{array}{l}\text { Transpira- } \\
\text { tion ratio } \\
(\mathrm{g} / \mathrm{g})\end{array}$} \\
\hline & & 1 & 5 & 10 & 15 & 20 & 25 & & \\
\hline IV & & 3.92 & 7.24 & 9.91 & 10.92 & 10.29 & 8.00 & 25.4 & 637 \\
\hline $\mathrm{V}$ & & 3.39 & 6.51 & 9.60 & 11.80 & 13.08 & & 25.5 & 500 \\
\hline VI & & 3.27 & 4.99 & 7.01 & 8.87 & 10.59 & 12.15 & 27.8 & 623 \\
\hline
\end{tabular}




\section{Results and discussion}

The daily amount of irrigation $(6.5 \mathrm{~mm})$ applied during the initial salination period was less than the underestimated ET. The additionally needed water was acquired from the still nonsaline lower part of the soil column rather than the much wetter, but saline upper part (Fig. 2); the water content there even increased till J5168. This clearly illustrates the unfavorable effect of salinity on root water uptake. At this early stage roots were not yet developed very much in the lower part, as could be observed through the glass wall of the soil container. The resulting smaller water uptake is reflected in the increase in water content towards the bottom.

From J5215 to J5249 daily irrigations again were less than ET, resulting in nearly uniform decrease of water content throughout the soil column (Fig. 3). On J5246 leaf water potentials, measured with thermocouple psychrometers, had decreased only slightly compared with those on J5239 (Table 2). Thereafter, plants began to be stressed badly, also indicated by the reduction in ET between day 20 and day 25 of growth period IV (Table 1). Leaf water potentials were not measured in this period, but later under similar conditions total potential decreased to about -190 $\mathrm{m}$. Starting on J5249, amounts of irrigation were increased to values above ET, but it was not until J5275 that water contents had increased such that drainage was
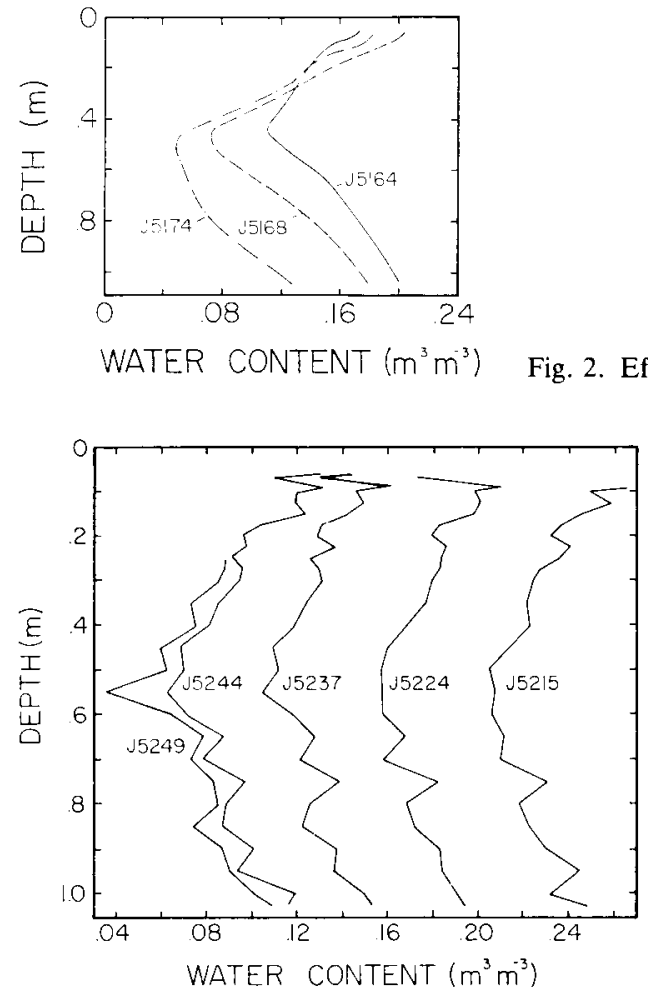

Fig. 2. Effect of initial salination on root water uptake.
Fig. 3. Water content profiles under daily deficit irrigation. 


\section{DIRKSEN}

Table 2. Total, osmotic, and turgor heads of leaf water, measured on excised leaf discs with thermocouple psychrometers after 6 hours of light (averages of 6 replicates).

\begin{tabular}{llll}
\hline $\begin{array}{l}\text { Ordinal } \\
\text { date }\end{array}$ & $\begin{array}{l}\text { Total } \\
(\mathrm{m})\end{array}$ & $\begin{array}{l}\text { Osmotic } \\
(\mathrm{m})\end{array}$ & $\begin{array}{l}\text { Turgor } \\
(\mathrm{m})\end{array}$ \\
$\mathrm{J} 5239$ & -96 & -154 & 58 \\
$\mathrm{~J} 5240$ & -90 & -148 & 58 \\
$\mathrm{~J} 5241$ & -100 & -139 & 39 \\
$\mathrm{~J} 5246$ & -125 & -162 & 37 \\
\hline
\end{tabular}

again obtained from the filter candles (Fig. 4). The extreme drying after J5244 (Fig. 3) apparently caused a permanent change in the soil packing at depth $z=0.55 \mathrm{~m}$, because the relatively low water content at that depth persisted during subsequent wetting (compare J5215 and J5275). Such changes in bulk density, and the volume occupied by root crowns (see Fig. 5a in Dirksen \& Raats, 1985) make absolute water contents measured indirectly by gamma ray attenuation inaccurate. All such water contents were adjusted based on gravimetric water content determinations at the completion of the experiments, but these phenomena remain a source of error, particularly in assigning soil hydraulic conductivities needed to calculate water flux densities, etc. However, changes in volumetric water content over relatively small time periods could be measured within a few thousandths.

The soil column became considerably more saline while it was being dried out due to deficit irrigation (Fig. 5, J5205, J5225 and J5244). The ensuing over-irrigations displaced the excess salt to the bottom of the soil column (J5292). The relative rates of the wetting front and the salinity front during this wetting process were analysed earlier (Dirksen, 1980). The salination of the column continued throughout the following growth periods (J6008). That is also apparent from Fig. 6, which shows the cumulative difference in amounts of salt brought into the soil column by

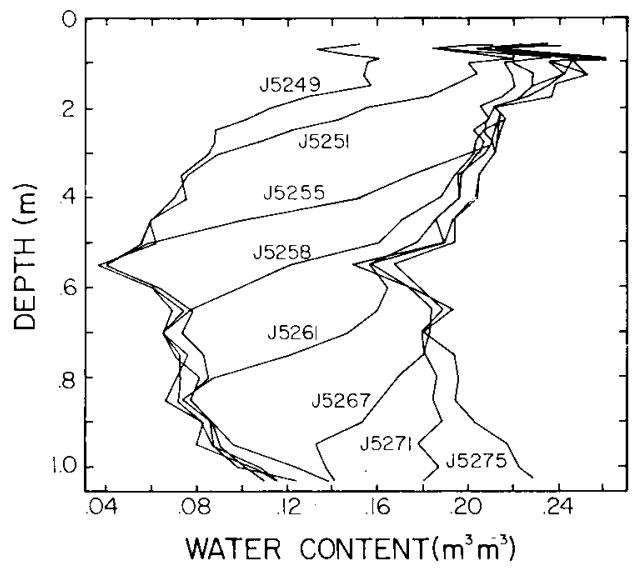

Fig. 4. Water content profiles under daily overirrigation. 
WATER AND SALT TRANSPORT IN DAILY IRRIGATED ROOT ZONE
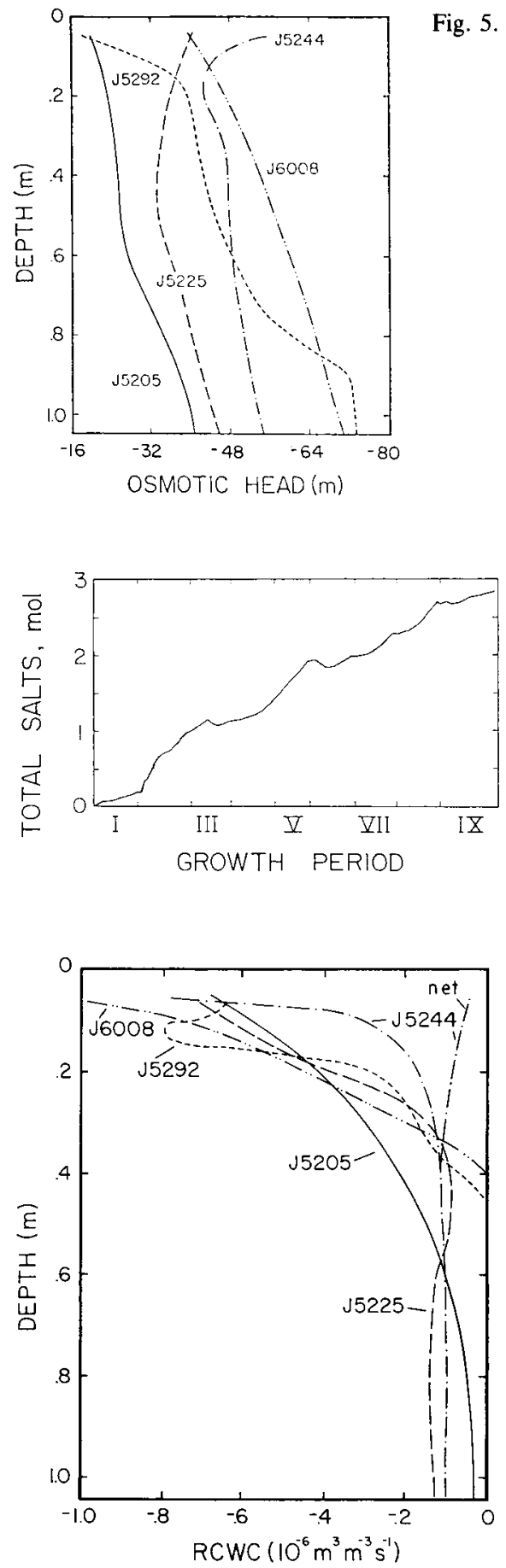

Fig. 5. Osmotic head profiles on five selected days.

Fig. 6. Cumulative amount of salt accumulated in soil column.

Fig. 7. Rate of change of water content (RCWC) profiles on days of osmotic head profiles shown in Fig. 5. 


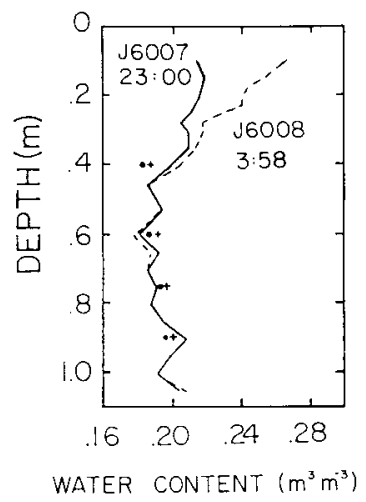

Fig. 8. Water contents measured before and after $12.9 \mathrm{~mm}$ irrigation on $\mathrm{J} 6007$, and derived from wetting soil water characteristic for minimum (O) and maximum (+) measured hydraulic heads (Fig. 10).

the irrigation water and discharged by the drainage water. Even after 230 days of daily irrigation, the salinity was far from having reached a steady state. This is true generally for high-frequency irrigation at low leaching fractions.

Distributions of rates of change of water content (RCWC) derived from gamma ray measurements on the days of the salinity distributions shown in Fig. 5, are given in Fig. 7. They are all averages for approximately 8.5-hour periods towards the ends of the 16-hour light periods. The irrigations all took place during the dark periods. Under the prevailing leaching fraction, the divergence of the flux density (DF) during the 8.5-hour periods was small enough for the RCWC distributions to be good approximations of the water uptake distributions (Dirksen, 1985). Thus, in saline soil with ample water supply (J5292 and J6008) water uptake by deep-rooting lucerne was shallow and confined to the zone in which water content increased daily (see Fig. 8) as a result of small irrigations which seldom exceeded $13 \mathrm{~mm}$. The net

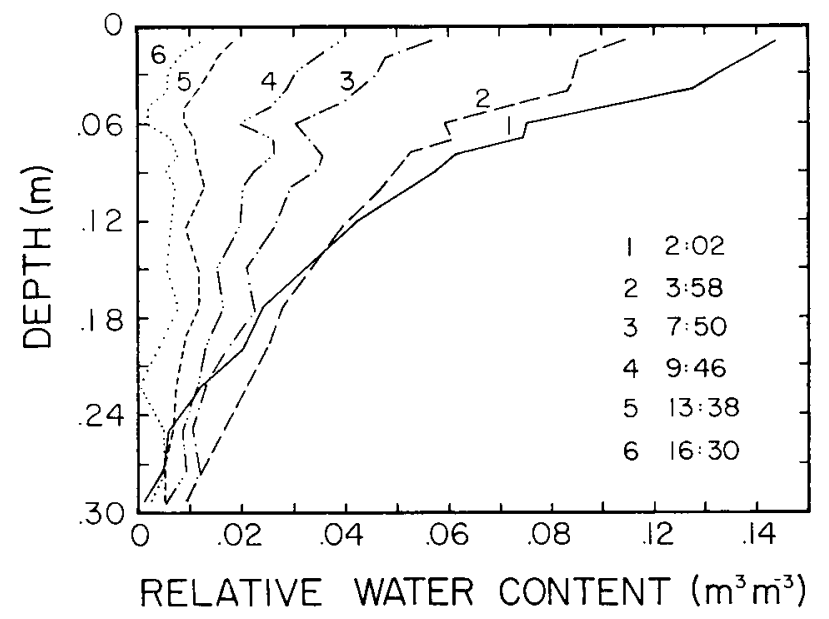

Fig. 9. Changes in water content in upper $0.30 \mathrm{~m}$ relative to water contents just prior to irrigation on J6007. 


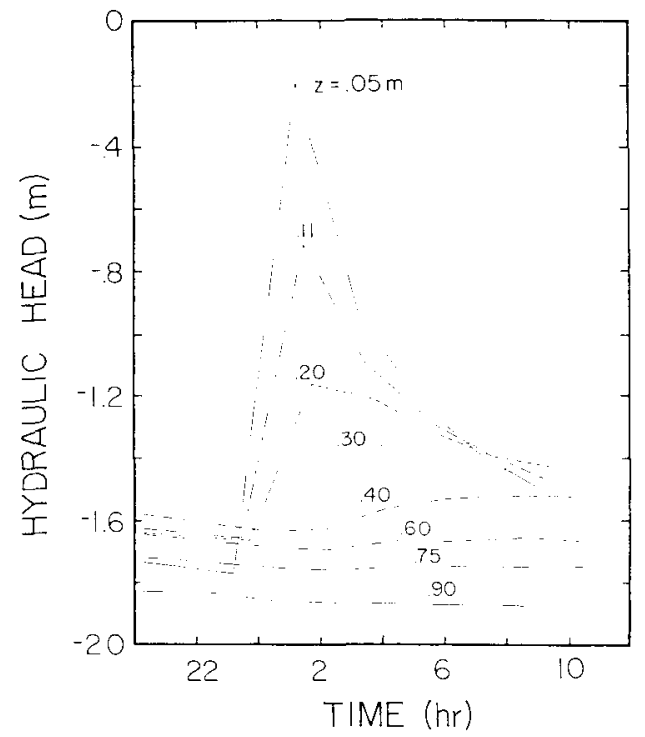

Fig. 10. Hydraulic heads at indicated depths before, during and after irrigation on J6007.

RCWC of J5244 is also indicated, as derived from gamma ray scans just prior to the two pertaining irrigations. The difference between the two curves for J5244 represents, therefore, water supplied by irrigation.

Water contents hardly changed below $z=0.35 \mathrm{~m}$ as a result of a $12.9-\mathrm{mm}$ irrigation which started around midnight on J6007 and was finished around 02:00 (Fig. 8 ). The changes in water content in the upper $0.30 \mathrm{~m}$ relative to the water contents just prior to this irrigation are shown more accurately in Fig. 9. The 58-minute gamma scans started at the indicated times; the 'average' times are about 26 minutes later. Redistribution is apparent between the scans of 02:02 and 03:58. After the lights were switched on at 04:00, water content changes mostly resulted from root water uptake. In fact, already at 08:00 the hydraulic head gradient was reversed above $z$ $=0.20 \mathrm{~m}$; prior to the irrigation it was reversed above $z=0.30 \mathrm{~m}$ (Fig. 10). These hydraulic heads were measured consecutively at the various depths with only one pressure transducer in 2-hour cycles, not frequent enough to show the rapid changes at the shallower depths. Below $z=0.60 \mathrm{~m}$, hydraulic heads were hardly influenced by the irrigation. These data support the assumption made in connection with Fig. 7, that at this low leaching fraction DF can be neglected compared to RCWC after 12:00, so that RWU can be estimated from experimental water content data only (Eq. 1). This is not possible at higher leaching fractions (Fig. 11b).

It was expected that, since water was being drawn from the column through the filter candles, water contents in the lower part of the column (Fig. 8) would have to correspond with measured pressure heads according to the drying soil water characteristic (Dirksen, 1985), but they were in fact much lower. On the other hand, the measured hydraulic head gradient and the hydraulic conductivity at the measured water contents were sufficient to accommodate the measured drainage 


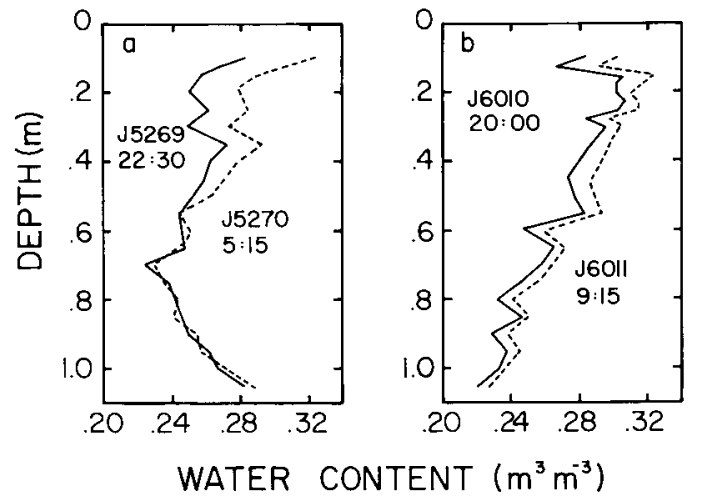

Fig. 11. Water content profiles before and after $21.4 \mathrm{~mm}$ irrigation in column being irrigated daily with tap water around $\mathrm{LF}=0.25$ (a); same for $20.0 \mathrm{~mm}$ irrigation with $h_{0}=$ $-22.0 \mathrm{~m}$ water at $\mathrm{LF}=0.50(\mathrm{~b})$.

flux density. Surprisingly, the water contents below $z=0.40 \mathrm{~m}$ are the same as those derived from the wetting soil water characteristic for the measured minimum (O) and maximum (+) hydraulic heads. In Fig. 8, water content increases slightly towards the bottom, indicating increasing pressure heads in that direction. This agrees with the measured hydraulic gradients which are less than unity. In a soil column irrigated daily with tap water around $L F=0.25$, water content increased even steeper towards the bottom than in Fig. 8 (Fig. 11a). In another column irrigated daily with water of $h_{0}=-22.0 \mathrm{~m}$ around $\mathrm{LF}=0.50$, water content decreased monotonously over the full depth, while the irrigation caused the water content to increase in the entire column (Fig. 11b). Under these conditions DF and RCWC are always of the same magnitude and RWU cannot even roughly be estimated without considering hysteresis. The water content profiles in both columns are within the range between the wetting and drying soil water characteristics for the measured pressure heads (Fig. 12).

These data illustrate what is true for high-frequency irrigation in general - except
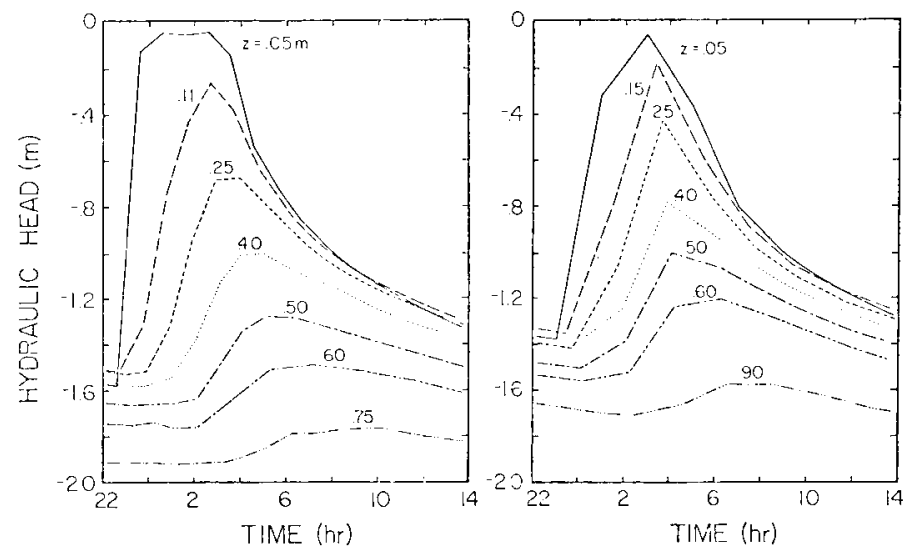

Fig. 12. Hydraulic heads at indicated depths at times of irrigations of Fig. 11. 
for the steady-state limit of continuous drip or trickle irrigation - that water and salt transport and root uptake cannot be described without taking into account hysteresis. Wetting and drying follow each other so rapidly and differ so much for various parts of the root zone that hysteresis has a major influence on the magnitude of DF.

The analysis of the data for daily irrigation has been hampered by the unavailability of a numerical simulation model which can handle water and salt transport taking into account hysteresis and allowing various root water uptake functions. Just recently I have acquired such a model. With this model, data reported here and in the references, and additional unpublished experimental results, I expect to make further progress in understanding how plant roots integrate non-uniform conditions in the water uptake process, especially under high-frequency irrigation. An intriguing question, for instance, is whether the effects of osmotic and pressure potentials on root water uptake are identical or only additive with different weights (Meiri, 1984; Shalhevet, 1984). The data of the non-daily irrigation experiments yielded a uniform relationship between leaf water potentials and total soil water potentials weighted according to RWU, without assigning different weights to pressure and osmotic potentials (Dirksen, 1985).

\section{Acknowledgement}

The experiments were carried out at the US Salinity Laboratory, Riverside, California, USA. I wish to thank my former colleagues for their help and advice.

\section{References}

Dirksen, C., 1980. The relative speed of wetting and salinity fronts under high-frequency irrigation of alfalfa with saline water. Proceedings International Symposium on Salt-affected Soils (Karnal, India), p. 243-250.

Dirksen, C., 1983. Principles of root water uptake, soil salinity and crop yield for optimizing irrigation management. Proceedings FAO-IAEA Symposium on Isotope and Radiation Techniques in Soil Physics and Irrigation Studies (Aix-en-Provence, France), p. 235-247.

Dirksen, C., 1985. Relationship between root uptake-weighted mean soil water salinity and total leaf water potentials of alfalfa. Irrigation Science $6: 39-50$.

Dirksen, C. \& M. J. Huber, 1978. Soil water flow model with two-dimensional automatic gamma ray attenuation scanner. Water Resources Research 14: 611-614.

Dirksen, C., J. D. Oster \& P. A. C. Raats, 1979. Water and salt transport, water uptake, and leaf water potentials during regular and suspended high frequency irrigation of citrus. Agricultural Water Management 2: 241-256.

Dirksen, C. \& P. A. C. Raats, 1985. Water uptake and release by alfalfa roots. Agronomy Journal 77 : 621-626.

Hoffman, G. J., C. Dirksen, R. D. Ingvalson, E. V. Maas, J. D. Oster, S. L. Rawlins, J. D. Rhoades \& J. van Schilfgaarde, 1977. Minimizing salt in drain water by irrigation management. Design and initial results of Arizona field studies. Agricultural Water Management 1: 233-252.

Hoffman, G. J., J. D. Oster, E. V. Maas, J. D. Rhoades \& J. van Schilfgaarde, 1984a. Minimizing salt in drain water by irrigation management - Arizona field studies with citrus. Agricultural Water Management $9: 61-78$.

Hoffman, G. J., J. D. Oster, E. V. Maas, J. D. Rhoades \& J. van Schilfgaarde, 1984b. Minimizing salt in drain water by irrigation management - Leaching studies with alfalfa. Agricultural Water Management 9: 89-104. 


\section{DIRKSEN}

Koorevaar, P., G. Menelik \& C. Dirksen, 1983. Elements of soil physics. Elsevier, Amsterdam, 228 pp. Meiri, A., 1984. Plant response to salinity: experimental methodology and application to the field. In: I. Shainberg \& J. Shalhevet (Eds.), Soil salinity under irrigation: Processes and management, p. 284297. Springer-Verlag, Berlin.

Rawlins, S. L. \& P. A. C. Raats, 1975. Prospects for high-frequency irrigation, Science 188: 604-610.

Shalhevet, J., 1984. Management of irrigation with brackish water. In: I. Shainberg \& J. Shalhevet (Eds.), Soil salinity under irrigation: Processes and management, p. 298-318. Springer-Verlag, Berlin. 